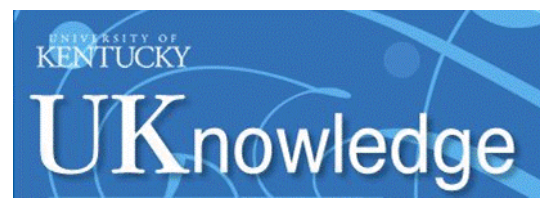

University of Kentucky

UKnowledge

\title{
The Effectiveness of Cervical Traction and Exercise in Decreasing Neck and Arm Pain for Patients With Cervical Radiculopathy: A Critically Appraised Topic
}

\author{
Shelby Baez \\ Old Dominion University \\ Johanna M. Hoch \\ Old Dominion University, johannaclark722@gmail.com \\ Timothy L. Uhl \\ University of Kentucky, tluhl2@uky.edu
}

Follow this and additional works at: https://uknowledge.uky.edu/rehabsci_facpub

Part of the Rehabilitation and Therapy Commons, and the Sports Sciences Commons

Right click to open a feedback form in a new tab to let us know how this document benefits you.

\section{Repository Citation}

Baez, Shelby; Hoch, Johanna M.; and Uhl, Timothy L., "The Effectiveness of Cervical Traction and Exercise in Decreasing Neck and Arm Pain for Patients With Cervical Radiculopathy: A Critically Appraised Topic" (2017). Physical Therapy Faculty Publications. 65.

https://uknowledge.uky.edu/rehabsci_facpub/65

This Article is brought to you for free and open access by the Physical Therapy at UKnowledge. It has been accepted for inclusion in Physical Therapy Faculty Publications by an authorized administrator of UKnowledge. For more information, please contact UKnowledge@lsv.uky.edu. 


\title{
The Effectiveness of Cervical Traction and Exercise in Decreasing Neck and Arm Pain for Patients With Cervical Radiculopathy: A Critically Appraised Topic
}

\author{
Digital Object Identifier (DOI) \\ https://doi.org/10.1123/ijatt.2016-0096 \\ Notes/Citation Information \\ Published in International Journal of Athletic Therapy and Training, v. 22, issue 5, p. 4-11. \\ (C) 2017 Human Kinetics
}

The copyright holder has granted the permission for posting the article here.

The document available for download is the authors' post-peer-review final draft of the article. 
The effectiveness of cervical traction and exercise in decreasing neck and arm pain for patients with cervical radiculopathy: a critically appraised topic

Shelby Baez, MS, LAT, ATC

Shelby is a doctoral student in the Health Services Research $\mathrm{PhD}$ program at Old Dominion University.

Johanna M. Hoch, PhD, LAT, ATC

Johanna is an Assistant Professor and the Director of Clinical Education in the Post-Professional Athletic Training Program at Old Dominion University

Timothy L. Uhl, PhD, ATC, PT

Timothy is a Professor and the Director of the Musculoskeletal Laboratory in the Division of Athletic Training at the University of Kentucky. 
1 Title: The effectiveness of cervical traction and exercise in decreasing neck and arm pain for

2 patients with cervical radiculopathy: a critically appraised topic

3 Key Points:

4 Clinical Question: Is there evidence to suggest intermittent cervical traction with cervical and

5 scapular strengthening exercises is more effective in decreasing neck and arm pain when

6 compared to cervical and scapular strengthening exercises alone in non-operative patients with

7 cervical radiculopathy?

8 Clinical Bottom Line: There is currently inconsistent, high-quality evidence that suggests that

9 the use of intermittent cervical traction in addition to strengthening exercises is more effective at

10 decreasing pain in non-operative patients with cervical radiculopathy when compared to

11 strengthening alone. Future research should continue to examine long-term outcomes associated

12 with cervical radiculopathy patients who use intermittent cervical traction as an intervention. 


\section{CLINICAL SCENARIO}

15 In patients diagnosed with cervical herniated discs or other neck injuries, radicular symptoms are 16 usually the primary cause of pain and discomfort. ${ }^{1,2}$ This discomfort, known as cervical

17 radiculopathy, includes pain and neurological symptoms that extend from the neck into the distal

18 extremity. ${ }^{3-5}$ Traditional therapeutic exercise for patients with cervical radiculopathy has resulted

19 in favorable outcomes; ${ }^{6}$ however, another frequently used intervention in the treatment of

20 patients with cervical radiculopathy is cervical traction. ${ }^{3-5}$ Cervical traction has been

21 recommended for patients who have peripheralization of symptoms with lower cervical mobility

22 testing, positive shoulder abduction sign, positive manual distraction test, positive upper-limb

23 tension test, and are 55 years of age or older. ${ }^{7}$ While minimal cost is associated with traditional

24 strengthening exercises, intermittent cervical traction units can cost beyond $\$ 3,000 .{ }^{8}$ Once the

25 patient is properly positioned in the device, the average treatment is approximately 15 minutes.

26 Despite the frequent usage of this modality by healthcare providers, effectiveness of the

27 treatment to support the use of cervical traction in these patients should be assessed. A synthesis

28 and critical appraisal of the best available evidence is needed to evaluate the effectiveness of the

29 intervention when compared to traditional strengthening exercises for future clinical

30 consideration.

\section{FOCUSED CLINICAL QUESTION}

32 Is there evidence to support intermittent cervical traction with cervical/scapular strengthening

33 exercises is more effective in decreasing neck and arm pain than cervical/scapular strengthening

34 exercises alone in non-operative patients with cervical radiculopathy? 
36 A computerized search was completed in September 2016 (Figure 1). The search terms used

37 were:

38 - Patient/Client group: Cervical Radiculopathy

39 - Intervention: Cervical Traction with Cervical and Scapular Strengthening Exercises

40 - Comparison: Cervical and Scapular Strengthening Exercises

41 - Outcome: Decreased Pain

42 Sources of Evidence Searched

$43 \quad-\quad$ Medline

- SPORTDiscus

- CINAHL Plus with Full Text

46 The criteria for study selection were as follows:

\section{Inclusion Criteria:}

- Studies classified as level 2 evidence or higher before critical appraisal. ${ }^{9,10}$

- Studies that included adult ( $>18$ years of age) patients.

- Studies that examined intermittent cervical traction and exercise compared to an alternative control group of just exercise.

- Studies published in English.

- Studies performed on human subjects.

\section{Exclusion Criteria:}

- Studies that did not measure patient-based outcomes to evaluate the effectiveness of

\section{Evidence of Quality Assessment}


59 Validity of the selected studies was determined using the physiotherapy evidence database

60 (PEDro) scale. The PEDro was selected due to the methodological design of the 2 eligible

61 studies. Two authors (SB, JH) independently reviewed the studies, completed the PEDro and

62 reviewed the completed appraisals to come to a consensus on study quality.

\section{RESULTS OF SEARCH}

\section{Summary of Search, Best Evidence Appraised and Key Findings}

65 - The literature search retrieved 5 studies (Figure 1). Two randomized controlled trials

66 (RCTs) ${ }^{11,12}$ met the inclusion criteria for this CAT and were categorized in Table 1. The level

67 of evidence as suggested by the Oxford Centre for Evidence Based Medicine in $2009^{10}$ was

68 used to identify eligible studies.

69 - Both studies compared the effects of traditional strength training exercises to traditional

70 strength training exercises and intermittent cervical traction. Patient-based outcomes were

$71 \quad$ collected in both studies. ${ }^{11,12}$

72 - The results of one study indicated mechanical intermittent cervical traction and exercise can

73 decrease neck and arm pain in patients with cervical radiculopathy at long-term follow-ups

74 when compared with patients who only received traditional strengthening. ${ }^{12}$ In contrast, the

75 other study identified no significant difference between groups who received intermittent

76 cervical traction and traditional strengthening as an intervention versus the use of a sham

77 intermittent cervical traction control group and strengthening exercises. ${ }^{11}$

\section{Results of Evidence Quality Assessment}

79 The Fritz et al. ${ }^{12}$ study received a PEDro score of 8/10 and the Young et al. ${ }^{11}$ study received a

80 PEDro score of 9/10. Neither study blinded the therapists. However, blinding the therapists poses

81 a difficult task due to the direct involvement of the therapist in the implementation of the 
82 intervention. Fritz et al. ${ }^{12}$ also received a deduction due to lack of blinding of subject group

83 assignment.

84 CLINICAL BOTTOM LINE

85 There is inconsistent, high quality evidence to support that cervical traction with strengthening

86 exercise compared to strengthening exercises alone is a more effective treatment at decreasing

87 pain in patients with cervical radiculopathy. One high-quality RCT demonstrated difference

88 between groups who utilized intermittent cervical traction versus traditional exercise. ${ }^{12}$ In

89 contrast, another high-quality RCT demonstrated no significant difference between groups who

90 utilized intermittent cervical traction and strengthening exercises versus those who utilized sham

91 intermittent cervical traction in combination with traditional exercises. ${ }^{11}$

\section{Strength of Recommendation}

94 There is grade B evidence to support the use of cervical traction with exercise compared to

95 exercise alone is more effective at decreasing pain in patients with cervical radiculopathy. The

96 grade of B is recommended by the Strength of Recommendation of Taxonomy. ${ }^{13}$ This

97 recommendation was given due to the inconsistent patient-oriented evidence included in this

98 CAT.

99 IMPLICATIONS FOR PRACTICE, EDUCATION AND FUTURE RESEARCH

100 The results of this CAT revealed inconsistent evidence regarding whether the use of

101 intermittent cervical traction with traditional exercise was more effective at decreasing neck and

102 arm pain in patients with cervical radiculopathy when compared to traditional exercise alone.

103 Fritz et al. ${ }^{12}$ compared three groups in their study. Patients were randomized into either an

104 exercise only group, an exercise with mechanical intermittent cervical traction group, or into an 
105 over the door cervical traction group. Results demonstrated that the mechanical intermittent 106 cervical traction and exercise effectively decreased patients' neck and arm pain as measured by 107 the Neck Disability Index (NDI) at 6-months compared to both groups, and these patients had 108 lower NDI scores at 12-months compared to the exercise group (Table 1). The arm pain intensity 109 ratings were also lower in the mechanical traction group when compared to the exercise alone 110 group at both 6 and 12-months. Interestingly, 53 patients (61.6\%) reported a successful outcome 111 on the global rating of change, regardless of treatment intervention, at 4-weeks. Additionally, 32 $112(37.2 \%)$ reported success at 6-months, and $35(40.7 \%)$ at 12-months. Thus, these results indicate 113 that patients in each group perceived their treatment to be better, regardless of their intervention.

114 Young et al. ${ }^{11}$ also examined the effects of intermittent cervical traction on pain reduction by 115 comparing two groups: an intermittent cervical traction plus traditional exercise group or sham 116 intermittent cervical traction plus traditional exercise group. No statistical differences in the 117 outcome measures were demonstrated between groups at either the 2-week follow-up or the 4118 week follow-up.

119 In both studies, the researchers utilized exercise plans that targeted cervical and scapular 120 strengthening. The exercise regimens used in both studies can be found in Table 1. However, 121 Young et al. ${ }^{11}$ also incorporated manual therapy for both groups. The intermittent cervical 122 traction parameters were also very similar between the two studies. For both studies, patients 123 were positioned supine at 15 degrees of cervical flexion. The total treatment time lasted 15 124 minutes with increases in traction force based on patient tolerance and centralization of 125 symptoms. Despite these similarities, both studies utilized different protocols for the actual 126 applications of the treatment. Fritz et al. ${ }^{12}$ applied a $60 / 20$ on and off cycle with an initial pull 127 force of $5.44 \mathrm{~kg}(12 \mathrm{lbs})$ and a relaxation force of 50 percent of the pull force. In contrast, Young 
128 et al. ${ }^{11}$ incorporated a 50/10 on off cycle with the traction force beginning at either $9.1 \mathrm{~kg}(201 \mathrm{bs})$

129 or $10 \%$ of the patient's body weight. The lesser weight was selected as the starting traction force.

130 It is possible the results varied between the studies due to the differences in treatment

131 parameters, inclusion of the mobilizations, and also the time points at which the outcomes were

132 collected.

Patients with neck pain and radicular symptoms were recruited to participate in both

134 studies. However, the studies incorporated different inclusion and exclusion criteria. In addition

135 to chief complaint and age criteria, Fritz et al. ${ }^{12}$ also included patients with a $>10$ on the Neck

136 Disability Index (NDI) as inclusion/exclusion criteria. However, Young et al. ${ }^{11}$ utilized a Clinical

137 Prediction Rule $(\mathrm{CPR})^{4}$ to evaluate patients for inclusion and exclusion which did not include a

138 self-reported symptoms score for inclusion. When examining the baseline NDI scores for the

139 patients included in each of the studies, the patients in Fritz et al. ${ }^{12}$ had a score of 32.8 (14.1)

140 while the patients included in Young et al. ${ }^{11}$ had an average score of $19.8(8.7)$ and 17.1 (7.4) for

141 the traction and exercise only group respectively. Thus, it appears Fritz et al. ${ }^{12}$ included patients

142 with high self-reported neck disability when compared to the patients in the Young et al. ${ }^{11}$

143 investigation. Furthermore, similar outcome measures were employed to determine treatment

144 effectiveness. Both studies incorporated the NDI and Numeric Pain Rating Scale (NPRS). Each

145 study also used a dimension specific outcome to measure fear of re-injury or kinesiophobia as

146 Fritz et al. ${ }^{12}$ included the Tampa Scale of Kinesiophobia and Pain Catastrophizing Scale and

147 Young et al. ${ }^{11}$ the Fear Avoidance Belief Questionnaire. Young et al. ${ }^{11}$ also included the Patient148 Specific Functional Scale.

Despite many similarities between treatments, patient population, and outcome measures, 150 the two studies reported differing results on the use of intermittent cervical traction in 
151 combination with exercise when compared to exercise alone for patients with cervical

152 radiculopathy. One of the biggest differences between the two studies is the time periods that

153 outcome measures were collected. Young et al. ${ }^{11}$ only collected outcome measures at 2 and 4-

154 weeks following treatment, while Fritz et al. ${ }^{12}$ collected outcome measures at 4-weeks, 6-months,

155 and 12-months post treatment. Fritz et al. ${ }^{12}$ demonstrated statistical differences for neck pain

156 intensity between intermittent cervical traction and traditional exercise at 4 -weeks $(\mathrm{p}=0.20)$,

157 while no significant differences between groups were demonstrated in the Young et al. ${ }^{11}$ study.

158 No other observed outcome measures resulted in statistical differences at 4 weeks in the Fritz et

159 al. ${ }^{12}$ study. However, Fritz et al. ${ }^{12}$ did find more notable significant differences at 6 -months and

160 12- months. Fritz et al. ${ }^{12}$ followed the patients for a longer period of time than Young et al. ${ }^{11}$,

161 which could suggest that intermittent cervical traction could be an effective intervention to

162 improve long-term outcomes in patients with cervical radiculopathy. Future research should

163 continue to measure long-term outcomes post-treatment in these patients to determine the

164 duration of treatment effectiveness.

165 Clinically, intermittent cervical traction does not appear to be contraindicated for patients

166 with cervical radiculopathy. While neither study demonstrated immediate decreases in pain

167 levels in patients, intermittent cervical traction did not increase pain levels and has the potential

168 for long-term benefits. Future studies should continue longitudinal research on patients with

169 cervical radiculopathy and the reduction of neck and arm pain with intermittent cervical traction.

170 In addition, future research should consider the clinical applicability of this tool in other patient

171 populations such as young-adults with cervical radiculopathy symptoms. This CAT should be

172 reviewed in two years (2018) to determine whether there is additional evidence that may change 
173 the recommendations of the use of intermittent cervical traction as an intervention for patients

174 with cervical radiculopathy.

1. Saal JS, Saal JA, Yurth EF. Nonoperative management of herniated cervical intervertebral disc with radiculopathy. Spine J. 1996;21(16):1877-1883.

2. Kumano K, Umeyama T. Cervical disk injuries in athletes. Arch Orthop Trauma Surg. 1986;105(4):223-226. 


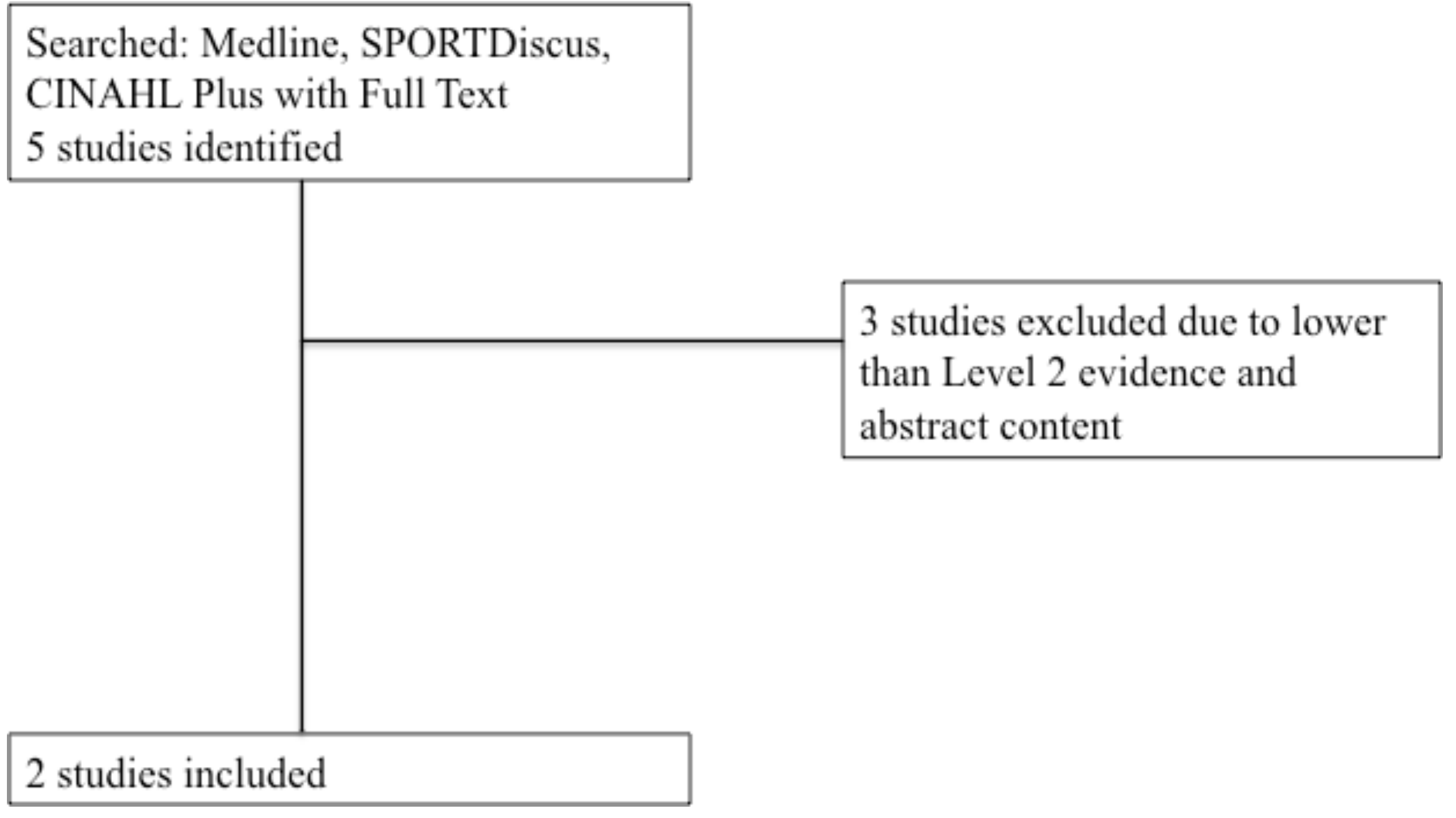

Figure 1. Summary of Search History and Included Studies 
Table 1 Characteristics of Included Studies

\begin{tabular}{|c|c|c|}
\hline Study Authors & $\begin{array}{l}\text { Fritz, Julie M. } \\
\text { Thackeray, Anne } \\
\text { Brennan, Gerard P. } \\
\text { Childs, John D. }\end{array}$ & $\begin{array}{l}\text { Young, Ian A. } \\
\text { Michener, Lori A. } \\
\text { Cleland, Joshua A. } \\
\text { Aguilera, Arnold J. } \\
\text { Snyder, Alison R. }\end{array}$ \\
\hline Study Title & $\begin{array}{l}\text { Exercise only, exercise with mechanical traction, or } \\
\text { exercise with over-door traction for patients with } \\
\text { cervical radiculopathy, with or without consideration } \\
\text { of status on a previously described subgrouping rule: } \\
\text { a randomized clinical trial }\end{array}$ & $\begin{array}{l}\text { Manual therapy, exercise, and traction for } \\
\text { patients with cervical radiculopathy: a } \\
\text { randomized clinical trial }\end{array}$ \\
\hline Study Participants & $\begin{array}{l}\text { Patients }(\mathrm{n}=86) \text { with neck pain and radicular } \\
\text { symptoms and }>10 \text { on the Neck Disability Index } \\
\text { (NDI). Patients were divided into three groups } \\
\text { Exercise Group (n=28) } \\
\text { Demographics and baseline values include, Mean } \\
(\mathrm{SD}) \text { : Age }=44.9(11.3) \text { years, duration of symptoms } \\
>6 \text { weeks }=8(28.6) \text {; self-rated general health= } \\
65.4(17.6), \text { NDI= 35(13.9); Neck Pain Intensity=4.4 } \\
(2) ; \text { Arm Pain Intensity=4.1 ( } 2.5) \text {; Tampa Scale of } \\
\text { Kinesiophobia=35.7 (7); Pain Catastrophizing } \\
\text { Scale=20.7 (12.3) } \\
\text { Mechanical Traction Group (n=31) } \\
\text { Demographics and baseline values include, Mean }\end{array}$ & $\begin{array}{l}\text { Patients with unilateral neck pain and } \\
\text { parasthesia; Met } 3 \text { out of } 4 \text { Clinical Prediction } \\
\text { Rule for CR (n=81) } \\
\text { MTEXTraction Group (n=45) } \\
\text { Demographics and baseline values include, } \\
\text { Mean (SD): Age =47.8 (9.9) years; Duration of } \\
\text { Symptoms (\%) } \leq 3 \text { months=27 (60), > } 3 \\
\text { months=18 (40); Neck Disability Index } \\
\text { (NDI)=19.8 (8.7); Patient-Specific Functional } \\
\text { Scale=3.5 (1.8); Numeric Pain Rating Scale=6.3 } \\
(1.9) \text {; Fear Avoidance Belief Questionnaire- } \\
\text { Physical Activity (FABQ-PA)=17.7 (7.4); Fear } \\
\text { Avoidance Belief Questionnaire-Work (FABQ- } \\
\text { W)=24.1 (17.2) }\end{array}$ \\
\hline
\end{tabular}




\begin{tabular}{|c|c|c|}
\hline & $\begin{array}{l}(\mathrm{SD}) \text { : Age=48.1 (10) years; Duration of symptoms } \\
>6 \text { weeks=12\%(38.7\%); Self-rate general } \\
\text { health=65.9 }(20.3) \text {; Neck Disability Index } \\
(\mathrm{NDI})=30.9(14.8) ; \text { Neck Pain Intensity=3.8 }(2.1) \text {; } \\
\text { Arm Pain Intensity=4.2 (2.2); Tampa Scale of } \\
\text { Kinesiophobia=36.1 (6.9); Pain Catastrophizing } \\
\text { Scale=18.9 (11.7) } \\
\text { Over-Door Traction Group (n=27) } \\
\text { Demographics and baseline values include, Mean } \\
(\text { SD): Age=47.6 (10.9); Duration of symptoms }>6 \\
\text { weeks=13\% (48.1\%); Self-rate general health=72.2 } \\
(18.1) ; \text { Neck Disability Index (NDI)=32.7 }(13.8) ; \\
\text { Neck Pain Intensity=4.5 (2.1); Arm Pain } \\
\text { Intensity=4.6 (2.6); Tampa Scale of } \\
\text { Kinesiophobia=36.7 (7.6); Pain Catastrophizing } \\
\text { Scale=17.1 (12.2) }\end{array}$ & $\begin{array}{l}\text { Sham Traction Group }(\mathbf{n}=\mathbf{3 6}) \\
\text { Demographics and baseline values include, } \\
\text { Mean (SD): Age=46.2 }(9.4) \text { years; Duration of } \\
\text { Symptoms \% } \leq 3 \text { months }=15 \text { (42), > } 3 \\
\text { months }=21(58) \text {; Neck Disability Index } \\
(\mathrm{NDI})=17.1(7.4) \text {; Patient-Specific Functional } \\
\text { Scale=3.3 (1.8); Numeric Pain Rating Scale=6.5 } \\
(1.7) ; \text { Fear Avoidance Belief Questionnaire- } \\
\text { Physical Activity (FABQ-PA)=18.3 (5.7); Fear } \\
\text { Avoidance Belief Questionnaire-Work (FABQ- } \\
\text { W)=18.7 (16.2) }\end{array}$ \\
\hline Inclusion/Exclusion Criteria & $\begin{array}{l}\text { Inclusion: Patients } 18-70 \text { years of age, chief } \\
\text { complaint of neck pain with symptoms extending } \\
\text { distal to acromioclavicular joint or caudal to superior } \\
\text { border of the scapular, >10 on NDI } \\
\text { Exclusion: History of surgery to the neck or thoracic } \\
\text { spine, recent motor vehicle accident, and red flags } \\
\text { indicative of serious or possible nonmusculoskeletal } \\
\text { condition, cervical spinal stenosis diagnosed by MRI } \\
\text { and/or CT, evidence of cervical myelopathy or } \\
\text { central nervous system involvement, or if patients } \\
\text { were unable to comply to treatment schedule }\end{array}$ & $\begin{array}{l}\text { Inclusion: Patients between } 18-70 \text { years old, } \\
\text { unilateral upper-extremity pain, paresthesia, or } \\
\text { numbers, } 3 \text { of } 4 \text { test of clinical prediction rule } \\
\text { positive. } \\
\text { Exclusion: History of previous cervical or } \\
\text { thoracic spine surgery, bilateral upper-extremity } \\
\text { symptoms, signs or symptoms of upper motor } \\
\text { neuron disease, medical red flags, cervical spine } \\
\text { injections in previous } 2 \text {-weeks, current usage of } \\
\text { steroidal medication for radiculopathy symptoms }\end{array}$ \\
\hline
\end{tabular}




\begin{tabular}{|c|c|c|}
\hline Intervention Investigated & $\begin{array}{l}\text { Patients were randomized into either an exercise } \\
\text { alone group, exercise plus mechanical traction group, } \\
\text { or exercise plus over-door traction. All patients } \\
\text { received } 10 \text { physical therapy visits over a } 4 \text {-week } \\
\text { period with each session lasting between } 30-45 \\
\text { minutes. } \\
\text { The exercise only group focused on cervical and } \\
\text { scapular strengthening. The exercises included: } \\
\text { Supine craniocervical flexion with feedback with } 10 \\
\text { contractions of } 10 \text { second holds; supine cervical } \\
\text { flexion for } 3 \text { set of } 15 \text { repetitions; seated cervical } \\
\text { flexion for } 30 \text { repetitions with } 10 \text { second holds; } \\
\text { scapular retraction using elastic bands or pulleys; } \\
\text { scapular-strengthening exercises including prone } \\
\text { horizontal abduction, sidelying forward flexion, } \\
\text { prone extension of each shoulder, and prone push- } \\
\text { ups with shoulder protraction for } 3 \text { sets of } 10 \\
\text { repetitions. Resistance was added as tolerated. } \\
\text { The mechanical traction group completed the same } \\
\text { interventions as the exercise only group with the } \\
\text { addition of intermittent cervical traction. Saunders } \\
3 \mathrm{D} \text { ActiveTrac or Chattanooga Triton Table was } \\
\text { used for the traction. The patient as positioned supine } \\
\text { in } 15^{\circ} \text { of cervical flexion with a } 60 / 20 \text { on off cycle. } \\
\text { The initial pull force was } 5.44 \text { kg (12lb) and was }\end{array}$ & $\begin{array}{l}\text { Patients were treated for an average of } 7 \text { visits } \\
\text { over } 4.2 \text { weeks. All treatments occurred in the } \\
\text { same order throughout the } 4.2 \text { weeks. Patients } \\
\text { began with postural education, manual therapy, } \\
\text { exercises, and then patients ended with } \\
\text { intermittent cervical traction or sham traction for } \\
15 \text { minutes. All patients were given a home } \\
\text { exercise program that focused on cervical and } \\
\text { scapular strengthening and received manual } \\
\text { therapy. } \\
\text { The exercise program consisted of cervical } \\
\text { retraction, cervical extension, deep cervical } \\
\text { flexor strengthening, and scapular strengthening. } \\
\text { Manual therapy consisted of a high-velocity, } \\
\text { low-amplitude thrust manipulation or a nonthrust } \\
\text { manipulation at the upper and mid-thoracic } \\
\text { spines of segments identified as hypomobile. } \\
\text { For both groups during intermittent cervical } \\
\text { traction or sham traction, patients were } \\
\text { positioned supine at approximately } 15^{\circ} \text { of } \\
\text { cervical flexion. For the intermittent cervical } \\
\text { traction group, the traction force started at } 9.1 \mathrm{~kg} \\
\text { (20lbs) or } 10 \% \text { of the patient's body weight. } \\
\text { Whichever weight was less was chosen as the } \\
\text { starting weight for traction. Traction force was } \\
\text { increased between } 0.91 \mathrm{~kg} \text { and } 2.27 \mathrm{~kg} \text { ( } 2-51 \mathrm{bs)}\end{array}$ \\
\hline
\end{tabular}




\begin{tabular}{|c|c|c|}
\hline & $\begin{array}{l}\text { increased based off of patient tolerance and } \\
\text { centralization of symptoms. The relaxation force was } \\
50 \% \text { of the pull force and each treatment lasted } 15 \\
\text { minutes. Traction was applied before or after } \\
\text { exercise per the physical therapist's decision. } \\
\text { The over-door traction group also received the same } \\
\text { exercise intervention, but used a Chattanooga } \\
\text { Overdoor Traction Device (DJO, LLC) during } \\
\text { treatment and daily at home. The initial traction } \\
\text { force was between } 3.63 \text { and } 5.44 \mathrm{~kg}(8-12 \mathrm{lb}) \text { and was } \\
\text { adjusted based off of patient tolerance and } \\
\text { centralization of symptoms. Maximum force was } \\
9.07 \mathrm{~kg} \text { ( } 20 \mathrm{lb} \text { ). Each treatment lasted } 15 \text { minutes and } \\
\text { occurred before or after exercise under the discretion } \\
\text { of the treating physical therapist. }\end{array}$ & $\begin{array}{l}\text { each visit, with a maximum force of } 15.91 \mathrm{~kg} \\
(35 \mathrm{lb} .) \text { for patients and an on/off cycle of 50/10. } \\
\text { Treatment was applied for } 15 \text { minutes. } \\
\text { For the sham traction group, only } 2.27 \mathrm{~kg}(5 \mathrm{lbs}) \\
\text { force or less was applied. }\end{array}$ \\
\hline Outcome Measures & $\begin{array}{l}\text { The Neck Disability Index, the } 11 \text { point neck pain } \\
\text { numeric intensity scale, and } 11 \text { point arm pain } \\
\text { numeric intensity scale. } \\
\text { All measures were assessed at baseline, 4-weeks, 6- } \\
\text { months, and } 12 \text {-months. }\end{array}$ & $\begin{array}{l}\text { The Neck Disability Index, Patient-Specific } \\
\text { Functional Scale, Numerical Pain Rating Scale, } \\
\text { Body Diagram, Fear Avoidance Belief } \\
\text { Questionnaire, and Satisfaction rating. } \\
\text { All measures were assessed at baselines, 2- } \\
\text { weeks, and 4-weeks. } \\
\text { The Global Rating of Change Scale was assessed } \\
\text { at } 2 \text { weeks and } 4 \text { weeks. }\end{array}$ \\
\hline Results & $\begin{array}{l}\text { Mechanical traction with exercises resulted in lower } \\
\text { pain for patients with cervical radiculopathy, }\end{array}$ & $\begin{array}{l}\text { There were no significant differences between } \\
\text { experimental group and sham group at 2-weeks }\end{array}$ \\
\hline
\end{tabular}




\begin{tabular}{|c|c|c|}
\hline & $\begin{array}{l}\text { primarily at long-term follow-ups. } \\
4 \text { weeks } \\
\text { The results indicated significant difference in neck } \\
\text { pain intesity scores between the mechanical traction } \\
\text { group }(1.4 \pm 1.4) \text { and the exercise group }(2.6 \pm 2.0) \\
\text { ( } \mathrm{p}=0.020) \text {, significant difference in arm pain } \\
\text { intensity between the exercise group }(1.6 \pm 2.0) \text { and } \\
\text { the over-door traction group ( } 1.6 \pm 2.0)(\mathrm{p}=0.002) \text {, } \\
\text { and significant differences in arm pain intensity } \\
\text { between the mechanical traction group }(1.4 \pm 1.6) \text { and } \\
\text { the over-door traction group ( } 1.6 \pm 2.0)(\mathrm{p}=0.017 .) \\
\text { There were no other significance differences between } \\
\text { groups at } 4 \text {-weeks. } \\
6 \text { months } \\
\text { The results indicated significant difference in neck } \\
\text { pain intensity scores and NDI between the } \\
\text { mechanical traction group ( } 1.1 \pm 1.4,9.2 \pm 9.4) \text { and the } \\
\text { exercise group }(3.0 \pm 2.3,22.5 \pm 14.1) \text { ( } \mathrm{p}=0.003 \text {, } \\
0.001) \text {. The results also indicated significant } \\
\text { difference in arm pain intensity between the exercise } \\
\text { group (3.2 } \pm 3.0) \text { and the over-door traction group } \\
(1.0 \pm 1.4 ; p=0.004) \text {, and significant differences in } \\
\text { NDI scores between the mechanical traction group } \\
(9.2 \pm 9.4) \text { and the over-door traction group } \\
(17.3 \pm 11.7 ; p=0.031 .) \text { There were no other }\end{array}$ & 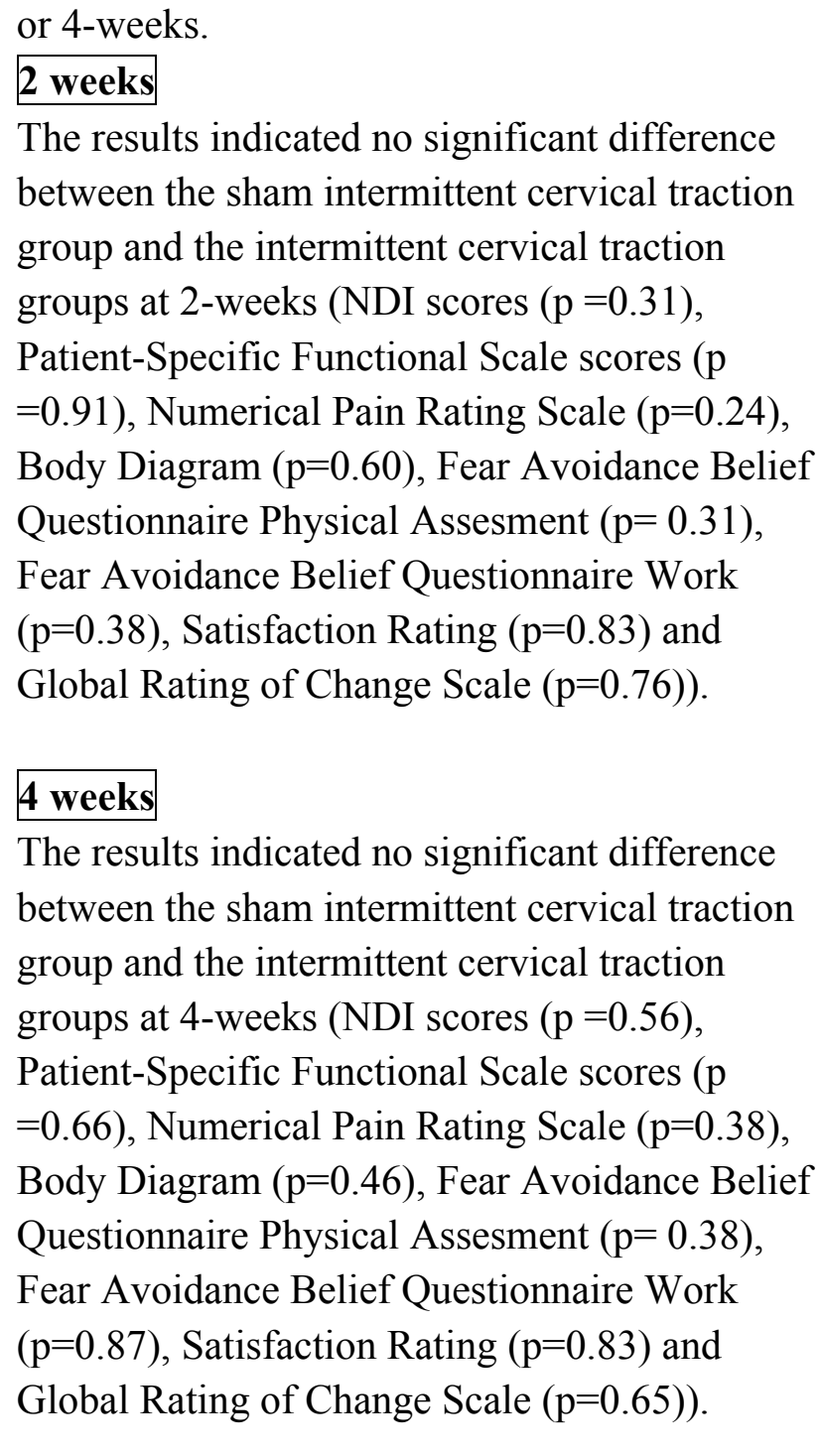 \\
\hline
\end{tabular}




\begin{tabular}{|l|l|l|}
\hline & $\begin{array}{l}\text { significance differences between groups. } \\
\mathbf{1 2} \text { months } \\
\text { The results indicated significant difference in NDI } \\
\text { scores between the mechanical traction group (10.3 } \\
9.0) \text { and the exercise group }(20.1 \pm 18.4 ; \mathrm{p}=0.046) . \\
\text { There were no other significance differences between } \\
\text { groups at } 12 \text { months. }\end{array}$ & \\
\hline Level of Evidence & 2 & 2 \\
\hline Support for the Answer & $\begin{array}{l}\text { The use of mechanical traction with traditional } \\
\text { exercise can decrease neck and arm pain in patients } \\
\text { with cervical radiculopathy. }\end{array}$ & $\begin{array}{l}\text { The use of traction did not decrease pain; } \\
\text { however, it is not contraindicated. }\end{array}$ \\
\hline
\end{tabular}

